\title{
Pedagogical Content Knowledge in Special Needs Education: A Case Study of an Art Project with the Multiple/Severe Handicapped
}

\author{
Taku Murayama \\ Department of Special Needs Education, Tokyo Gakugei University, Japan
}

Copyright $(2016$ by authors, all rights reserved. Authors agree that this article remains permanently open access under the terms of the Creative Commons Attribution License 4.0 International License

\begin{abstract}
This paper focuses on a project in teacher education through art activities at the undergraduate level. The main theme is art activities by university students and multiple and severe handicapped students. This project has two significant points for the preparation of special education teachers. One point is the opportunity for field work. Even students majoring in special education have insufficient opportunities for field research in places where there are multiple handicapped students because of restricted accessibility, including limitations attributable to medical care. The other point concerns professional learning. In the Japanese system, certification for special education teachers is based on that of regular schools. The students learn about the subject knowledge with non-disabled students in mind, so they have a few chances to learn and inquire about pedagogical content knowledge for severely handicapped students. Both qualitative and narrative analysis has been attempted in this research. The main topics are the university students' awareness and recognition of the communication styles-including non-verbal ones-of the multiple handicapped, and the change in students' views regarding multiple handicapped students' learning and activities through the art activities.
\end{abstract}

Keywords Pedagogical Content Knowledge (PCK), Art, Severe/Multiple Handicaps, Pre-service Teacher Education

\section{Introduction}

\subsection{Pedagogical Content Knowledge: The Agenda}

In the study of pedagogical content knowledge (PCK), we face a number of difficult dimensions. The first is that there are many concepts regarding the definition of PCK. Since Lee Shulman (1986) first introduced the concept of PCK, a large number of concepts has arisen as researchers have taken an interested in it and have attempted to make it clear. The second is that the outline of PCK and how to utilize this concept in the context of student learning is not so clear.

The National Council for Accreditation of Teacher Education (2002) in the United States gives a partial definition of PCK.

[PCK is the] interaction of the subject matter and effective teaching strategies to help students learn the subject matter. It requires a thorough understanding of the content to teach it in multiple ways, drawing on the cultural backgrounds and prior knowledge and experiences of students (NCATE, 2002). NCATE has also had an influence on general teacher education in the United States. This definition is also informative for exploring the character of PCK, even though it concerns the area of special needs education. PCK has been said to have a critical significance for teacher education (Davis and Simmt, 2006), and thus research on the definition and character of PCK should be promoted.

The case survey in this paper inquiries into the notion and character of PCK in special settings. However, the paper aims not at universal notions of PCK, but at the submission of the situated character of PCK to special needs education, and moreover PCK in this paper describes one applied to the subject of art in specialized and hospitalized settings.

The case presented is an ongoing art activity project by university students and multiple and severely handicapped students. This project has meaning as field work and the opportunities for professional learning about teaching in a specific subject.

In this research, a field work survey has been attempted. The focus is on university students' awareness and recognition of the learning and communication styles-including non-verbal ones-of the multiple handicapped, and the change in university students' views regarding the multiple handicapped students' learning and activities through the art activities. 
Table 1. Contents List for the Subject of Art in Special Schools in Japan

"Arts and Crafts" (Primary)
$1^{\text {st }}$ Level
1. To have an interest in drawing, creating, decorating, and so on.
2. To play with formative arts using familiar materials such as clay, wood, and paper.
1. To draw, model, and decorate what they see and feel.
2. To become familiar with and use materials and tools such as clay, crayons, scissors, and paste.
$\quad 3^{\text {rd }}$ Level
1. Thoughtfully drawing and creating, as well as decorating and using what students have seen, felt, and imagined.
2. Using materials and tools for their purpose thoughtfully.
3. Showing their own artworks to each other among friends, and noticing the appeal of shape, color, and ways of expression of plastic artworks and
so on.
"Art" (Secondary: all levels)
2. Understanding and using various types of materials and tools.
3. Being familiar with the beauty of nature and plastic artworks.

\subsection{Japanese Context of Special Education around PCK}

As seen in the previous section, it is difficult to define PCK, the case analysis and application of PCK into the field of special educational settings needs to be analyzed.

Manner (2002) suggests the arts provide natural and functional learning opportunities beyond simply learning an academic subject. Manner's focus is not on the field of special needs education, but this indicates a case for application to the area of special education. The course of study for special education schools in Japan, the curriculum contents of the subject of "arts and crafts" (at the primary level) and the "arts" (at the secondary level) are regulated, and are as shown in Table 1.

The list gives all of the described contents in the course of study of art in the national curriculum of Japan. The reason for these scanty descriptions is that the curriculum contents are highly dependent on students' situations, including the types and severity of disabilities and illness, the accumulation of knowledge and skills in their daily living, and their environment, and then it is necessary to think of the students' individuality in special educational settings. Teachers should devise appropriate teaching methods and materials for their students' individualized situations. As the students show a wide variety of developmental and health conditions, the common contents in the national curriculum are not applicable to many students. Thus teachers in special schools may arrange programs for their students using PCK, and this is why the concepts of PCK are critical even in special educational settings.

Moreover, in the Japanese system, the certification for special education teachers is based on the license for regular schools. For special education certification, teachers are requested to gain the elementary or secondary school teachers' certification as a so-called "basic license." The standard of preparation for special education teachers is that the learning of each subject is based on the preparation for regular school teachers. For example, university students majoring in special needs education take a course in art for elementary schools, but there is no course such as "art for the disabled." Thus students have few opportunities to learn and think about the school subject for learners with special needs. The students learn about the subject knowledge with non-disabled students in mind, and therefore have few chances to learn and inquire about the pedagogical content knowledge for severely handicapped students.

\section{PCK in Art}

\subsection{The Character of Art for All Learners: Literature Review}

Gregoire \& Lupinetti (2005) suggests that art is to be a great equalizer in education, regardless of abilities or disabilities. Because the arts are largely non-verbal and focus on creativity, students can participate in various ways. Gregoire and Lupinetti also insist, "Fortunately, the arts can reach all types of students." Consequently, success in school for many students can be supported and facilitated through an arts program being infused throughout the curriculum. This may go as far as to include students with multiple handicaps and disabilities. The curriculum would be infused with art for multiple handicapped students and the students in pre-service teacher training.

Cornett (2003) advocated that integrating the arts into the curriculum would have particular relevance to diverse classrooms. One relevance is that the arts are fundamental to all cultures and time periods and therefore provide a natural view into the social contribution of other cultures. The arts are primary forms of communication, because they are based on imagination and cognition. Additionally, the arts may focus on alternative forms of assessment and evaluation (Gregoire, et al. 2005).

Art includes partly nonverbal activities, and is therefore suitable for students with considerable linguistic limitations, but what Gregoire and colleagues suggest would not necessarily be the best place to start a discussion. The experience of creating visual art by communicating 
with/without simple verbal language would provide the basis for language development.

\subsection{PCK in Art for the Multiple Handicapped}

While developmental approaches toward content for severely handicapped learners have the advantage of tradition and a wealth of excellent examples to adapt from, some educators question their appropriateness and efficacy (Ferguson, 1987). Available data suggest that severely handicapped students do not acquire skills in the normal developmental sequence, often because of the complicating factors of sensory, medical, and motor difficulties. Ferguson also stresses that developmental approaches focus on determining content - "what to teach" - with little concurrent emphasis on instructional techniques and strategies, the "how to teach."

\section{3. "Touching, Holding, and Feeling" Project}

\subsection{Outline of the Project}

The extra-curricular program the "Touching, Holding, and Feeling" Project was developed to support learning about art at a special school for the severely disabled and volunteering students at Tokyo Gakugei University (TGU). This project contains a formative activity workshop in the school, an exhibition in the art hall in TGU with a trial lesson by teachers in this school, and a workshop by art students in TGU.

In terms of participants, the group now consists of 28 students at TGU, eight students at a special school with the collaboration of three teachers, and another special school has proposed to join us from the point of the exhibition in TGU. Students at TGU prepared the materials for the workshop with some research in the school beforehand. Important support was given by the Western-style painting at TGU, and from teachers at the special school.

The project was originally designed and organized around networking between the university and schools in the neighborhood with arts activities. The department of fine arts of TGU set up this project in collaboration with a local special school.

In the preparation process of the workshop, Shulman's implication of PCK and pedagogical reasoning has been noticed. According to Shulman, pedagogical reasoning involves observation, reflection, ongoing formative evaluation, and assessment as a part of a process of understanding judgment, and actions, which lead to "wise pedagogical decisions" (Shulman, 1987). In addition, having contribution for the professional development of teachers, post reflection of lesson study has been drawn in a direct line.

The school with which we collaborated is for students with severe physical impairments and with needs for constant medical observation. This small school is therefore attached to the National Institute of Neurology and Psychiatry and our workshop has been partly held in the daily caring room in the hospital or sometimes in a bedroom in a ward. The project itself has a six-year history with the Department of Fine Arts at TGU, but this is the first year that our laboratory in the Department of Special Needs Education has joined the project at the request of the laboratory of Western-style paintings. Taking this opportunity of joining the project, components of university students' study as an extra-curricular program for pre-service teacher training were implemented. The mission of this project is to design a network between a university and a local school and to train undergraduate and graduate students by endowing them with a specific background (art or special needs education) with the contents of fine arts, as well as understanding the particular needs of diverse learners (especially severely multi-handicapped teens, as in this project) with respect to teaching. The aim of the project is to immerse university students in the restricted situation of the impaired students to provide direct experiences with knowledge and skill development.

\subsection{Process of the Workshop}

In the workshop in the hospitalized class, one student with multiple impairments and two or three university students make up a working group, which then attempted to give concrete shape and sharing to the younger student's ideas. Special attention has been given to the role of students in both schools in making artworks. Because of the unbalanced number of participants (three students in TGU per junior in average, as well as teachers and nurses who participate for health reasons), we are paying attention to how we can promote the younger students' independence and activeness.

The project suggests collaboration and practical inquiry that exists between the disciplines, as well as the application of concepts to new situations, since even university students in the Department of Special Needs Education may not approach severely impaired students in the usual way. The university students work together in the project to deepen their content knowledge and skills, which include the effective use of discourse in the interdisciplinary collaborative groups.

This project is committed not only to providing special school students with experience in art, but to provide the university students with an experience of producing decoration with disabled students and special education teachers.

At the beginning of the project, we recommended that the art students investigate the possibilities and issues of art activities for the disabled, and suggested that students of special needs education inquire into the deepening of knowledge and teaching contents of the subject (in this case, art). Later, the project expanded into collaborative activities through the gathering and selecting of materials, choosing 
the topic (the topic this year is "sky (with clouds)"), and inquiring into how to address the disabled students (in Japanese "koekake"), and so on. Furthermore, the project is helping university students integrate pedagogy and content in the various phases of activities in this project workshop.

\subsection{Reflection on the Workshop}

After a series of activities (this is not necessarily the completion of their work, because of the limits arising from the learners' medical and health conditions), the disabled students show their artworks to each other, and the university students explain the concept (e.g. fantasy, dreamland, or a story they like) and the important points of the artwork (e.g. a pink-based tone in a pretty image) on behalf of the young students who are unable to speak.

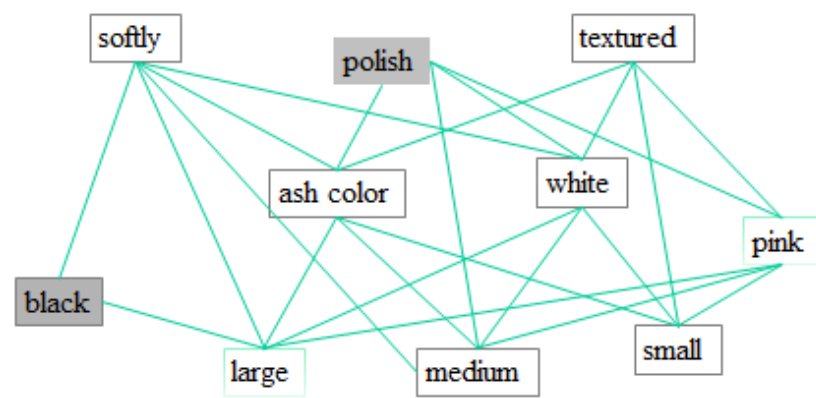

Figure 1. Simplified model of the selection of materials (for clouds) by the young students.
Figure 1 shows the types of materials used for the clouds by the younger students. In the process of making and decorating the background of the sky, the clouds represented the younger students' own feelings.

Imray and Hinchcliffe (2014) suggest the key elements of the individual arts may be pattern and texture, color, line and tone, shape, form and space. Materials are made of cotton, felt, white paper, plastic tape, Japanese paper, and so on. In the workshop, university students have been supportive of the younger students. This was not only in artistic aspects; the students had to pay attention to the young person's line of sight, position of the body, slight signs of emotion and so on, because the younger students are confined to bed. As with other art activities, our project stresses color, shape, and space as a result of the limits of each junior students' abilities and functions for writing and drawing. However, this is not enough for the disabled students' participation. In order that the multiple handicapped students may participate in the art activities, cognitive and kinesthetic elements such as touching should be implemented, and then our preparation of materials has enabled us to achieve better outcomes.

We have held some reflection meetings and the university students had some comments after the workshop. The reflection was based on free-form discussion and students had comments about things they noticed in the process of workshop. Table 2 shows a partial list of student comments after the workshop in July 2015.

Table 2. Reflection on the art workshop by university students

\begin{tabular}{|c|c|c|}
\hline Phase & Aspects & Examples of university student comments \\
\hline \multirow{4}{*}{$\begin{array}{l}\text { Artistic } \\
\text { phase }\end{array}$} & Enjoying the materials & $\begin{array}{l}\text { What do the disabled students like? } \\
\text { What's the meaning of the art experience itself? } \\
\text { Touching unusual materials, which they have few opportunities to do. }\end{array}$ \\
\hline & Artistic aspects & $\begin{array}{l}\text { Selection of materials (cloth, colors, etc.) } \\
\text { Selection of adhesive bond (ease of use, texture of bond, etc.) }\end{array}$ \\
\hline & $\begin{array}{l}\text { Teaching and creation } \\
\text { process }\end{array}$ & $\begin{array}{l}\text { U students learned from the disabled students through their reactions, what they liked, } \\
\text { etc. } \\
\text { A process of visualization was developed from the concept of the sky and clouds. }\end{array}$ \\
\hline & The artwork & $\begin{array}{l}\text { How to have disabled students form an image or make sense of the artwork as a whole } \\
\text { (each group made a separate part of the artwork). } \\
\text { The students' personal preferences for colors (this can be researched in advance, but is } \\
\text { that good for us?) }\end{array}$ \\
\hline \multirow{3}{*}{$\begin{array}{l}\text { Teaching } \\
\text { phase }\end{array}$} & Kinesthetic aspects & $\begin{array}{l}\text { The process of multiple disabled students' body tonus. (The art activities would be } \\
\text { more effective after reducing their tonus.) } \\
\text { Motion (even if only a little) creates possibilities for a new sense of touch. } \\
\text { Noticing the line of sight as an effective approach for smooth contact. }\end{array}$ \\
\hline & $\begin{array}{l}\text { Non-verbal } \\
\text { communication }\end{array}$ & $\begin{array}{l}\text { How to recognize that communication has been established and what conditions can } \\
\text { be set up. } \\
\text { The importance of communication in teaching practice. } \\
\text { The importance for U students to observe the younger student's eyes (including the } \\
\text { line of sight). } \\
\text { Communication style through design and production of the artworks. }\end{array}$ \\
\hline & $\begin{array}{l}\text { Collaboration among } \mathrm{U} \\
\text { students }\end{array}$ & $\begin{array}{l}\text { (Many art students said they learned about) how to open up to the disabled students } \\
\text { and understand their intentions (mainly y/n). } \\
\text { (Many SNE students said they learned about) how to develop the image of an artwork } \\
\text { in situations involving limited materials and conditions. } \\
\text { Differences in viewpoint and the way to talk (even in the same situation): } \\
\text { E.g. It's finished! (art student) / Well done! (SNE student) } \\
\text { Very good! (art student) / That's a beautiful color! (SNE student) } \\
\text { Further expectations for future collaborative learning. }\end{array}$ \\
\hline
\end{tabular}


A variety of comments can be seen and we can also note that they include comments about both the artistic phase and the teaching phase. It is, of course, difficult to divide the activities into two phases, but it is helpful for inquiring into the character of PCK in art for the disabled.

Overviewing this table, PCK consists of knowledge about the subject of art and the knowledge of teaching or understanding disabled children. The disabled students' disabilities and illnesses have a possibility of restricting their learning potential, and thus in the preparation of educational materials it is preferable to arrange for them to be easy to use. In special educational settings, since individualized teaching is stressed, it may be possible to prepare materials for individual use unless the disabled student's learning is not isolated in the classroom context and close human relations exist with friends and teachers.

Through what is reflected in this day's workshop, kinesthetic perspectives and the attention to non-verbal communication has also been emphasized. Disabilities and handicaps may bring about linguistic limits in the reflection, and therefore teachers' knowledge regarding the context of learning with the understanding of disabilities and the restrictiveness of learning is a high requirement in the classroom.

In the arena of teacher education, reflection by the teacher has been attracted attention for the professional development of teachers in lesson study. Ramanaidu et al. (2014) suggests that in music education teacher training, a crucial element in teacher training programme is a planning lessons, and the pre-service teachers during practicum by giving them ideas and discussing with them during the planning stage. The project of ours also enabled to university students of each discipline meet opportunities through the planning workshop including preparing the materials, contents, and special move for the education, care and treatment for the younger multiple handicapped.

As for the International Classification of Functioning, Disability and Health (ICF) by WHO, the social function and the degree of "Participation" of the disabled has stressed. This workshop has not directly aimed at the upgrading the physical function of the multiple handicapped students, but cover the promotion of "Participation" of theirs by the university students' teaching arts and supporting communication, even if the younger has been unspeakable.

\section{Conclusion and Discussion}

Art is essentially said to be concerned with the making and sharing of meanings and stimulates the process of personal growth. Arguably this gives form and expression to an inner drive to externalize images; perhaps we all have some inner need to communicate, to find forms of expression and to symbolize or encapsulate our experiences; ways in which we may all find a sense of personal validation. In school we need to ensure that these are achievable by ensuring that children of all abilities develop confidence and appropriate skills. The capacity for all art forms to motivate, to encourage self-esteem, to stimulate the imagination, curiosity, and encourage children generally to investigate, are major outcomes of any learning experience for a child with severe learning difficulties (Carpenter \& Hills, 2002).

From a different viewpoint, Imray and Hinchcliffe (2014) argue that a creative curriculum is necessary for those with profound and moderate learning difficulties (PMLD) and it is also advocated that the disabled students are directly involved in curriculum development. It is said that it is not very easy to assess whether those with PMLD will benefit in the same way, simply because the cognitive functioning levels of those with profound learning difficulties may preclude a number of the elements of learning that we might aim for with those with severe learning difficulties. Art is, however, process based, and careful observation of small and subtle changes in those with PMLD will indicate learning taking place over time. At the very least, art offers real opportunities for joint ventures, an inclusive curriculum and an addressing of the issues raised in the Quality of Life debate (Lyons and Cassebohm, 2010).

One of the major problems surrounding special education is treatment compatible with increasing severity, duplicability, and diversity of the disabilities and health conditions of students. In order for university students to become thoughtful teachers being capable of meeting their students' needs, they must see the possibilities for the application of the materials that they are learning. Learning experiences may offer opportunities for university students to investigate and explore the contents.

In the context of inclusive education, the intervention training has so meaningful in the following two points. The first is the practical engagement for university students in the field of the special needs education and the treatment. The multiple handicapped students' treatment has been accompanied with co/medical care and the teaching and instruction should be checked on a case-by-case basis in the real context in the classrooms. The second is the small teaching group with the university students majoring Arts, the students majoring special needs education, and the teachers working for the attached special school has been collaborating with their professionality and the practical research of students. Arts students had a chance to make their artistic performance for applying to the multiple and severe handicapped students, and the special needs students had an opportunities to make their pedagogical and psychological knowledge connected the real appearance of the severe handicapped students, both university students has received the technical support by the teachers in the school. This collaborating practice of teachers and teaching staffs has had made the basis of inclusive setting of education.

The case indicated in this presentation is an ongoing project, further analysis and inquiry is required, including some theoretical framework. In this paper, the character of PCK in the subject of art is shown as a complex assembly of the subject content knowledge and the knowledge of teaching, but to specify the features of specialized 
curriculum contents would be informative in teacher education both for special school teachers and teachers coming into inclusive education.

\section{Acknowledgements}

This paper forms one part of "Research into Professionalism in Special Education Teachers" financed by a Tokyo Gakugei University Grant-in-Aid for Research by Young Scholars (Fiscal 2015). Thanks are due to the Office of Promoting Educational Practice Research of Tokyo Gakugei University; the laboratory of Western-style painting; and the members of our project at TGU. I also offer my personal thanks to the many participants in this project.

\section{REFERENCES}

[1] Barrett, F. \& Green, K. (2009). Pedagogical Content Knowledge as a Foundation for an Interdisciplinary Graduate Program. Science Educator, 18(1), 17-28.

[2] Carpenter, B. \& Hills, P. (2002). Rescuing the arts: The sunmoves project, The SLD Experience, 32, 22-24.

[3] Cornett, C. E. (2003). Creating meaning through literature and arts: an integration resource for classroom teachers $\left(2^{\text {nd }}\right.$. ed $)$. Upper Saddle River, Merrill/Prentice Hall.

[4] Davis, B. \& Simmt, E. (2006). Mathematics-for-Teaching: An Ongoing Investigation of the Mathematics that Teachers (Need to) Know. Educational Studies in Mathematics, 61(3), 293-319.
[5] Ferguson, D. L. (1987). Curriculum Decision Making for Students with Severe Handicaps: Policy and Practice. New York, Teachers College Press.

[6] Gregoire, M., \& Lupinetti, J. (2005). Supporting diversity through the arts, Kappa Delta Pi Record 41(4), 159-163.

[7] Imray, P. \& Hinchcliffe, V. (2014). Curricula for teaching children and young people with severe or profound and multiple learning difficulties: practical strategies for educational professionals. Abington: Routledge.

[8] Lyons, G. \& Cassebohm, M. (2010). Life satisfaction for children with profound intellectual and multiple disabilities, Kober, R. (ed) Enhancing the quality of life of people with intellectual disabilities. Social Indicators Research Series 41, 183-204.

[9] Manner, J. C. (2002). Arts throughout the curriculum. Kappa Delta Pi Record, 38(1), 17-19.

[10] Ministry of Education, Culture, Sports, Science and Technology-Japan (2009) "Course of Study for Schools for Special Needs Education" (original in Japanese).

[11] National Council for Accreditation of Teacher Education (NCATE) (2002). Professional Standards for the Accreditation of Schools, Colleges, and Department of Education .

[12] Ramanaidu, R. R. et al. (2014). Pre-Service Music Teachers' Concerns before a Practicum Stint. International Education Studies, 7(8), 35-43.

[13] Shulman, L. (1986). Those who understand: Knowledge growth in teaching. Educational Researcher, 15(2), 4-14.

[14] Shulman, L. (1987) Knowledge and teaching: Foundations of a new reform, Harvard Educational Review, 57(1), 1-22. 